\title{
The Society for Gastrointestinal Intervention. Are We, as an Organization of Disparate Disciplines, Cooperative or Competitive?
}

\author{
Richard A. Kozarek \\ SGI President 2008-2010; Digestive Disease Institute, Virginia Mason Medical Center, Seattle, WA, USA
}

This is the Fourth Annual Meeting of the Society for Gastrointestinal Intervention, a multi-disciplinary group of practitioners committed to a minimally invasive approach to both the diagnosis and treatment of digestive disorders. The key concepts are minimally invasive and multi-disciplinary which can be construed as practicing in parallel with occasional lines of procedural and clinical interaction or inter-disciplinary in which patients are acutely cared for by a team, with treatments tailored to the patient and not the discipline that touches the patient first. In reality, many of us exist in both worlds. Most universities and large clinics are structured in departments along traditional training lines. As such, Interventional Radiology is housed in the Radiology Department, Laparoscopic Surgery (and potentially NOTES), as a component of the General Surgery Division, and Therapeutic Endoscopy usually resides within a gastroenterology structural framework. These divisions have historically been kept separate by multiple forces: salaries and budgets usually reside in a larger division. As a group, the amount of practice devoted to $\mathrm{Gl}$ disorders is variable (for instance, minimally invasive surgeons may approach the adrenal glands or lung lesions in some institutions and interventional radiologists often sample tissue in multiple areas outside the $\mathrm{Gl}$ tract, and by virtue of access to the vascular tree, can stent, embolize, or TPA almost any area of the body), as well as inherent differences in our individual abilities to access organs. I have already mentioned that angiographic capabilities allow the interventional radiologist access to virtually every $\mathrm{Gl}$ organ and those capabilities allow therapeutic options for bleeding, tumor embolization, stenting of stenotic lesions, and formation of intravascular shunts. As such, there is very limited interdisciplinary competition here although cap- sule endoscopy as well as double and single balloon enteroscopy have improved the endoscopist's diagnostic and potential therapeutic reach. However, many of these diagnostic triumphs for obscure or massive GI bleed are simply to tattoo lesions that require surgical removal by laparoscopic or traditional surgery. Cooperation. However, there are potential competitive areas in the treatment of $\mathrm{Gl}$ vascular lesions also. Whereas endoscopic band ligation has supplanted EVS, splenic devascularization, and most shunting procedures for patients with esophageal varices, endoscopic techniques have had less long-term success with glue injection for gastric varices. Multiple randomized, prospective trials have suggested therapeutic primacy of TIPS with embolization of recalcitrant vessels as an option or back-up. Despite this, therapeutic endoscopists have learned valuable lesions from our IR colleagues and studies are underway using endoscopically injected coils in addition to cyanoacrylate in an attempt to improve acute and long-term bleeding control. Nor is there any major competition in the treatment of primary or metastatic liver tumors by chemoembolization, RF current, or other thermal modalities, although selected patients with single lesions or multiple lesions isolated to a single lobe may be better handled surgically if there is curative intent. Finally, there is little IR, and progressively less, surgical competition for the treatment of high-grade dysplasia or superficial malignancies in the setting of Barrett's esophagus which are adequately treated in most patients by mucosectomy, RF ablation, or cryotherapy but require direct mucosal visualization to direct this therapy. The same has proven true for many years for colorectal polyps, superficial gastric cancers, and ampullary adenomas that had historically all been treated with major surgical resections. Still, there are

Correspondence to: Richard A. Kozarek

Digestive Disease Institute, Virginia Mason Medical Center, 1100 9th Ave., PO Box 900 (C3-GAS), Seattle, WA 98101, USA

Tel: +1-206-223-2319, Fax: +1-206-223-6379, E-mail: gasrak@vmmc.org

DOI: $10.5009 /$ gnl.2010.4.S1.S1 
many patients with advanced lesions who are good operative candidates who should be approached with conventional or minimally invasive surgery with the intent of operative cure. Cooperative, not competitive. The potential for competition between disciplines comes in mundane situations and clinical settings that have historically been "owned" by a single discipline. On the one hand, placement of PEGS and PEJs, initially done endoscopically, can be done with equal facility and occasional failure, by endoscopists and interventional radiologists, reserving failed attempts for minimally invasive surgery. What resources are utilized with these three methods? Are there advantages to defining the mucosa of the gut lumen in all, or even a subset of patients? By way of contrast, acute cholecystectomy tubes in high surgical risk patients have usually been the domain of the radiologist, although I described transcystic duct gallbladder decompression endoscopically $2 \frac{1}{2}$ decades ago. With the advent of new devices delivered under EUS control, the gallbladder will now be readily accessible endoscopically. What does this mean both for the acutely ill patient without a window to approach their gallbladder radiologically? Will this play a bit part and a cooperative technique to expand our therapeutic armamentarium or will it become competitive therapeutically not only for IR but for minimally invasive surgeons? The same may be said for EUS's ability to inject genes, caustics, or chemo-therapeutic agents into organs adjacent to the lumen. What is the role of TNFerade injection into unresectable pancreatic cancers and the role of absolute alcohol or Taxitol to treat cystic neoplasms of the pancreas? The real issue of competition or cooperation between the disciplines comes when treating patients with unresectable and obstructing GI neoplasms, from my perspective. The latter may occur almost anywhere in the Gl tract but, of course, are more commonly noted proximally (esophagus, stomach, duodenum) and distally (left colon) as well as proximal and distal biliary obstructions. Recognizing that the occasional mid-small bowel and many proximal colon lesions are better handled with an endoscopic approach because of loss of vector force and difficulty pushing a catheter through large diameter, acutely angulated lumens, all others are fair game from my perspective. To my knowledge, although there are studies demonstrating the superiority of SEMS over open or laparoscopic bypass for malignant gastric outlet obstruction insofar as return of gut function, hospitalization time, and resource utilization, there are no studies demonstrating the superiority of one discipline or another in the placement of SEMS. Nor have cost data emerged suggesting the superiority of one technique over another from a cost standpoint. Unless or until we have such studies, this suggests to me that institutional interest and expertise should play a major role in how these unfortunate patients have continuity of their $\mathrm{Gl}$ tract re-established. The situation is a bit more complex in pancreaticobiliary malignancy. There are 2 prospective randomized trials (level 1 evidence) that suggest that patients with proximal strictures (Bismuth II-IV) in conjunction with bile duct and gallbladder cancer, respectively, may be more successfully stented percutaneously and certainly it is easier to deliver brachytherapy or PDT under protocol to these patients who have indwelling external drains. In contrast, there are no data, positive or negative, to suggest that PTBD is a preferable treatment for distal biliary malignant obstruction, and in most parts of the world, the endoscopic approach has supplanted the percutaneous one just as metal stents have replaced plastic prostheses to preclude recurrent bouts of stent dysfunction and need for additional ERCP. The question posed at the beginning of this syllabus contribution: Are we competitive or cooperative? The answer is obviously both but, hopefully, our choice of treatment should depend less on who touches the patient first and more on skill sets within an institution and what is the best treatment for this particular individual. The importance of the SGI is technical and informational cross-fertilization. If your university or clinic will not allow blurring of training barriers to put therapeutic endoscopists, minimally invasive surgeons, and interventional radiologists together as a department or institute, you can nevertheless work together as a team in the best interest of your patients. (Gut Liver 2010;4(Suppl. 1):S1-8)

Key Words: Therapeutic endoscopy; Interventional radiology; Minimally invasive surgery

The Society for Gastrointestinal Intervention (SGI) was envisioned by its founders as a multi-disciplinary group of practitioners committed to a minimally invasive approach to the diagnosis, but, more importantly, the treatment of digestive disorders. As originally formulated, it included interventional radiologists and gastroenterologists but in reality the latter group encompasses not only medical and surgical endoscopists but also minimally invasive surgeons, including those interested in NOTES. The key concepts are minimally invasive and multi-disciplinary which can be construed as practicing in parallel with occasional lines of procedural and clinical interaction. Alternatively, and more in line with the philosophy of the SGI, care of patients with digestive disorders is inter-disciplinary, in which patients undergo minimally invasive therapy, if appropriate, by a team with treatments tailored to the patient and not the discipline which touches the patient 


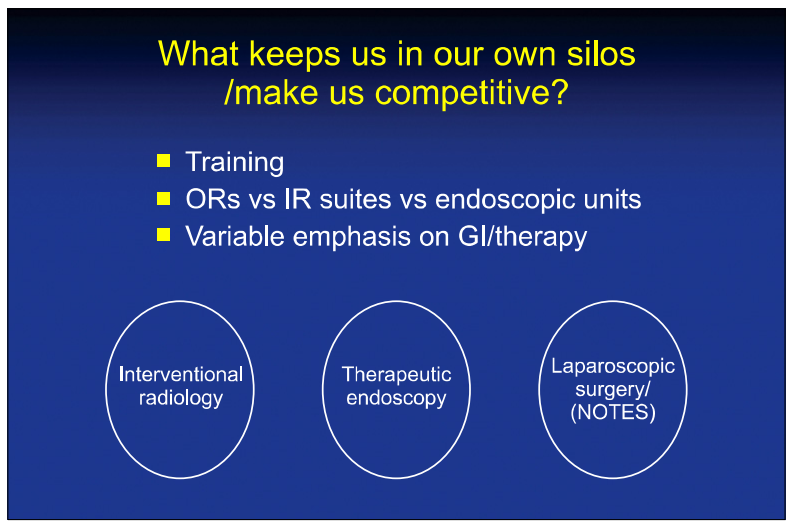

Fig. 1. What makes minimally invasive therapies competitive?

first.

\section{TRAINING}

\section{What factors keep us apart?}

Although in reality, many of us practice both in parallel and in an interdisciplinary fashion, most universities and large clinics are structured in departments along traditional training lines. ${ }^{1-5}$ As such, Interventional Radiology is housed in the Radiology Department, Laparoscopic Surgery (and potentially NOTES) as a component of the General Surgery division, and Therapeutic Endoscopy usually resides within a Gastroenterology, or less commonly, General Surgery structural framework. ${ }^{6-9}$ This training and subsequent geographic isolation tends to structurally, and to some extent philosophically, separate the disciplines. As such, there are very few institutions in which operating rooms, endoscopy units, and interventional radiology suites are housed in a common space (Fig. 1).

\section{Economics and scope of practice}

It is naive to discount economic and intellectual incentives as a source of "turf battles" between the disciplines. A more subtle factor enforcing competition, however, is both a variable emphasis on gastrointestinal disorders as well as a different emphasis on therapy. It is not surprising that gastroenterologists and GI endoscopists place a significantly greater emphasis on GI disorders than minimally invasive surgeons who may also treat thyroid disease, place permanent vascular access catheters, and do the occasional venous stripping of the lower extremities. The latter discipline, in turn, has significantly more of a GI practice than the average interventional radiologist who spends a considerable portion of his time placing drainage tubes throughout the body, obtaining short-term vascular access, lysing clots, and a vari-

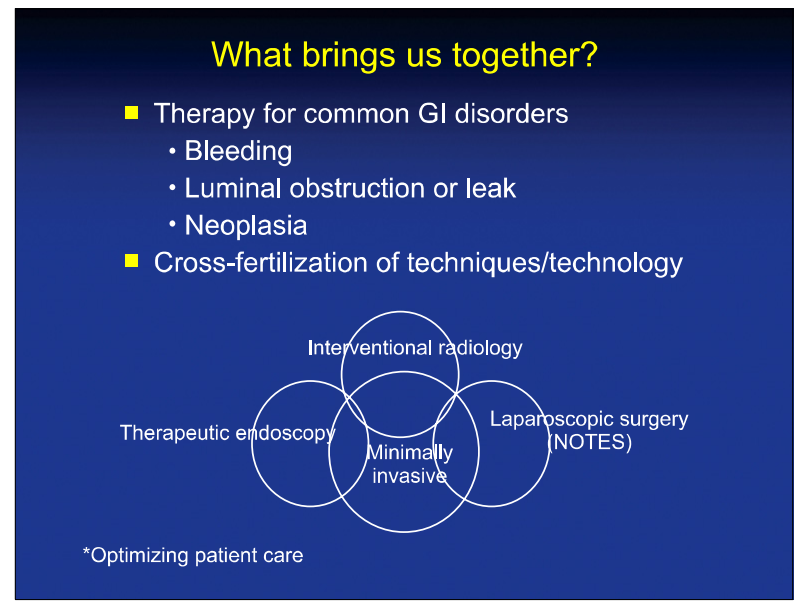

Fig. 2. What brings minimally invasive therapeutic practitioners together?

ety of other interventions. On the other hand, interventional radiologists and general/minimally invasive surgeons undertake therapy much more often than gastroenterologists who may spend a predominance of their time screening dyspeptic patients or surveilling colons for recurrent polyp formation.

\section{WHAT BRINGS THE DISCIPLINES TOGETHER?}

\section{Treatment of common disorders}

Despite the divergence in training, space, and degree of emphasis on GI disorders and the therapy rendered, there are numerous areas of interface that should bring closer interdisciplinary care. For instance, all of the specialties treat GI neoplasia or its consequences, luminal obstruction and leak, as well as gastrointestinal bleeding. In addition, there is substantial overlap of techniques and technology and the potential for significant cross-fertilization (Fig. 2).

\section{WHO TREATS WHAT RIGHT NOW AND WHAT IS COMPETITIVE?}

However, in order to define the nature of this cross-fertilization, we should define what discipline controls which GI disorder currently, and whether these treatment boundaries are inviolate. Although there are probably multiple disease states that are treated primarily by a single discipline, there are some generalizations. Resectable malignancy and symptomatic gallbladder and appendiceal disease in good risk patients is currently handled surgically. ${ }^{10-13}$ Endoscopists, in turn, are the primary diagnosticians and therapists for amenable GI bleeding lesions and most non-malignant mucosal neoplasms (Fig. 3)..$^{14,15}$ 

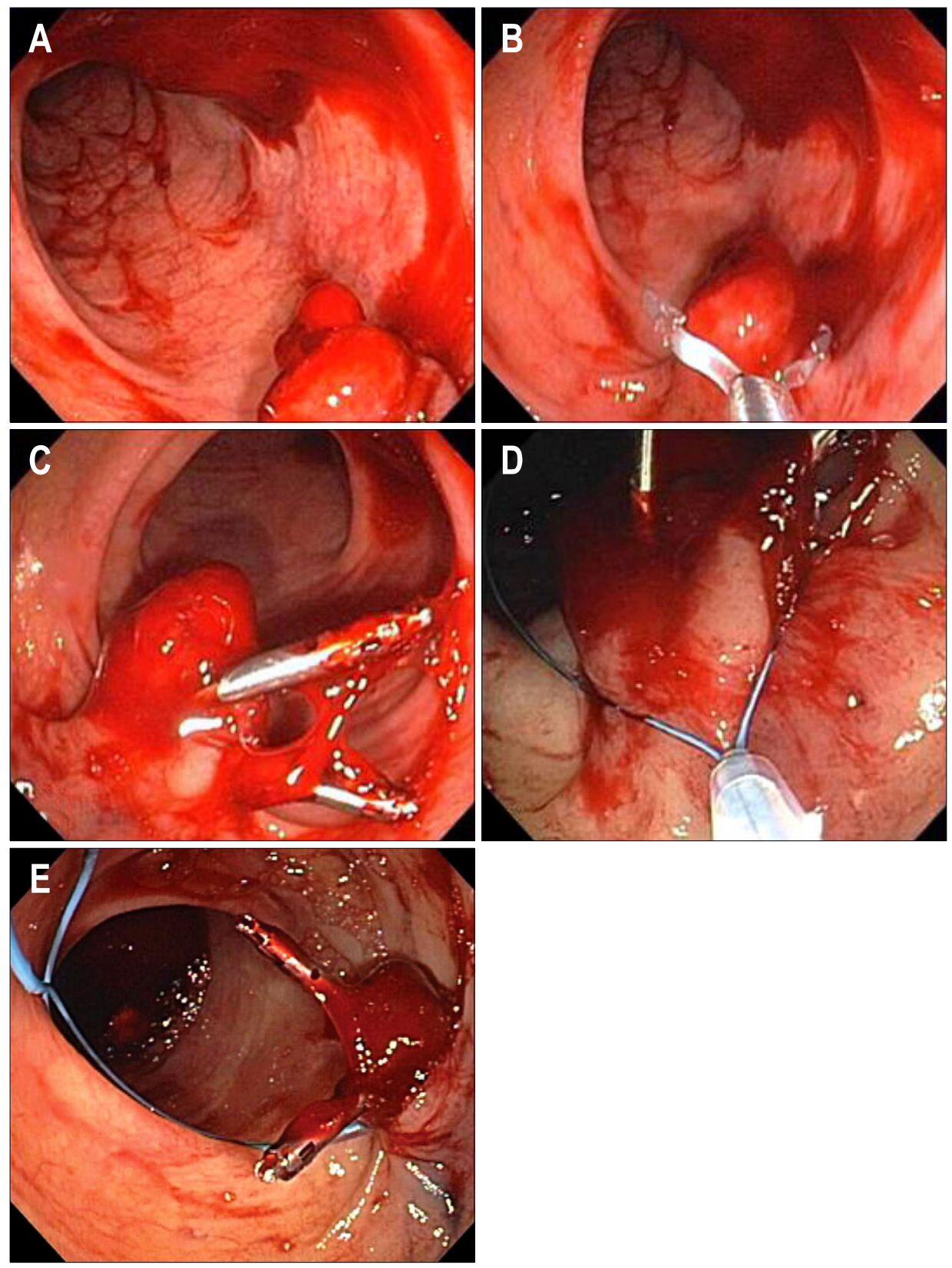

Fig. 3. Postpolypectomy bleeding (A) treated with clip placement (B, C) and a subsequent endoloop snare $(D, E)$.

Finally, interventional radiologists are pre-eminent for therapy delivered either percutaneously or through the vascular tree (Fig. 4). ${ }^{16,17}$

Competitive proceedings, that is, those that are routinely done by all three disciplines include insertion of gastrostomy and jejunostomy tubes, palliation of obstructing malignancy in non-resectable patients (Fig. 5), and less commonly, gall bladder drainage in the high risk patient. ${ }^{18-21}$ For the most part, the latter has been relegated to the percutaneous approach, although endoscopically placed trans-sphincter gall bladder stents and na- so-gall bladder drains can be inserted at time of endoscopic retrograde cholangiopancreatography (ERCP) and are useful if there is no radiographic "window" for biliary access. $^{22}$ Moreover, there have been a number of new technologies and techniques allowing endoscopic ultrasound (EUS). access to the gall bladder and bile duct to allow acute decompression, usually into the duodenum. ${ }^{23,24}$ Additional studies have reported a variety of endoscopic techniques to create a permanent cholecystoduodenal fistula thereby opening up the gall bladder to non-surgical therapy, particularly in the surgically unfit patient and 

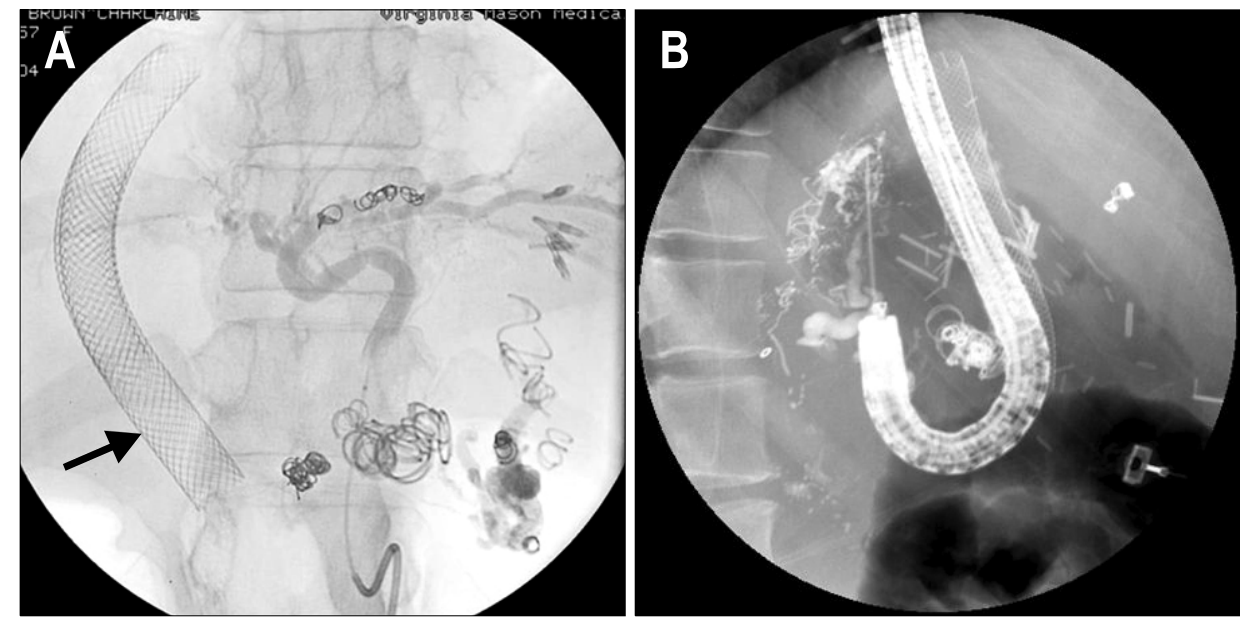

Fig. 4. Portal-hypertension patient with TIPS x 2 (arrow) undergoing additional embolization for repeated gastric variceal hemorrhage (A). Despite the above intervention, recurrent variceal hemorrhage necessitated endoscopic cyanoacrylate-glue sclerosis of a residual bleeding varix (B).

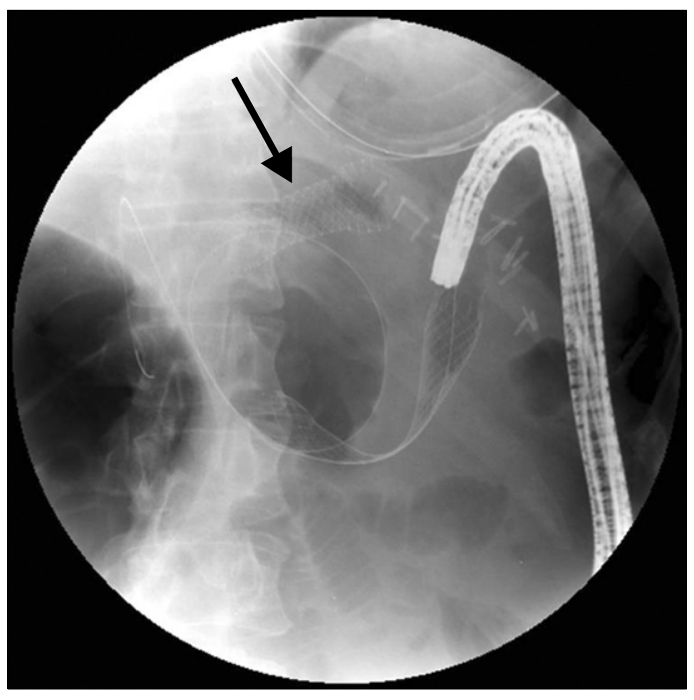

Fig. 5. Abdominal plain film demonstrating a markedly dilated colon in a patient with an obstructing transverse colon malignancy that was treated with a self-expandable enteral metal stent (SEMS). Note the gastric SEMS (arrow) in this patient who initially presented with gastric outlet obstruction.

possibly in those with symptomatic cholelithiasis who refuse surgical intervention.

\section{WHAT MINIMALLY INVASIVE PROCEDURES ARE CURRENTLY COOPERATIVE?}

There are a plethora of cooperative interventional procedures that are typified by the patient with variant anatomy in whom endoscopic access may prove difficult or impossible. ${ }^{25}$ An example is transgastric ERCP in patients with Roux en Y gastric bypass. ${ }^{26,27}$ This cooperation may include percutaneous gastrostomy tube placement by IR, tract maturation, and subsequent dilation 4-6 weeks later to allow insertion of a duodenoscope. Alternatively, lapa- roscopic access into the stomach followed by trocar or rigid sigmoidoscope insertion can be done with immediate transgastric access to the pancreaticobiliary tree, and often is possible in minutes as opposed to the $90-120 \mathrm{mi}$ nutes needed for single or double balloon-assisted ERCP.

There are other examples of interdisciplinary cooperation. Historically, these have included rendezvous procedures including placement of a percutaneous transhepatic biliary drain (PTBD) in patients with impacted common bile duct stones or benign or malignant biliary strictures in whom access by initial ERCP has proven unsuccessful (Fig. 6) ${ }^{28,29}$ These combined procedures are in evolution, however, as patients with unresectable malignant obstructive jaundice can have indwelling self-expandable metal stents (SEMS) placed percutaneously without need for a repeat ERCP. Likewise, EUS-assisted access to the biliary tree may make PTBD unnecessary in some tertiary referral centers but data requiring comparable safety and cost are recommended before a major shift in practice pattens can be recommended. ${ }^{23,24}$

Additional and commonplace interdisciplinary procedures occur in the setting of iatrogenic biliary injury and leak. In this setting, it may be inadequate to place a biliary stent to facilitate drainage and close a leak. Significant bilomas require concomitant biloma drainage, either percutaneously or less commonly, laparoscopically. Alternatively, individuals who sustain a biliary injury with concomitant devascularization of the bile duct can be converted from an emergent to elective surgical bypass following endoscopic or percutaneous biliary decompression. ${ }^{17,21}$ This is in contrast to patients who sustain a biliary injury alone, a situation responsive to sequential balloon dilation and multiple biliary prosthesis placement in approximately $80 \%$ of the patients.

Additional areas of cooperation between the disciplines occurs in the setting of obstructing malignancies. While a 

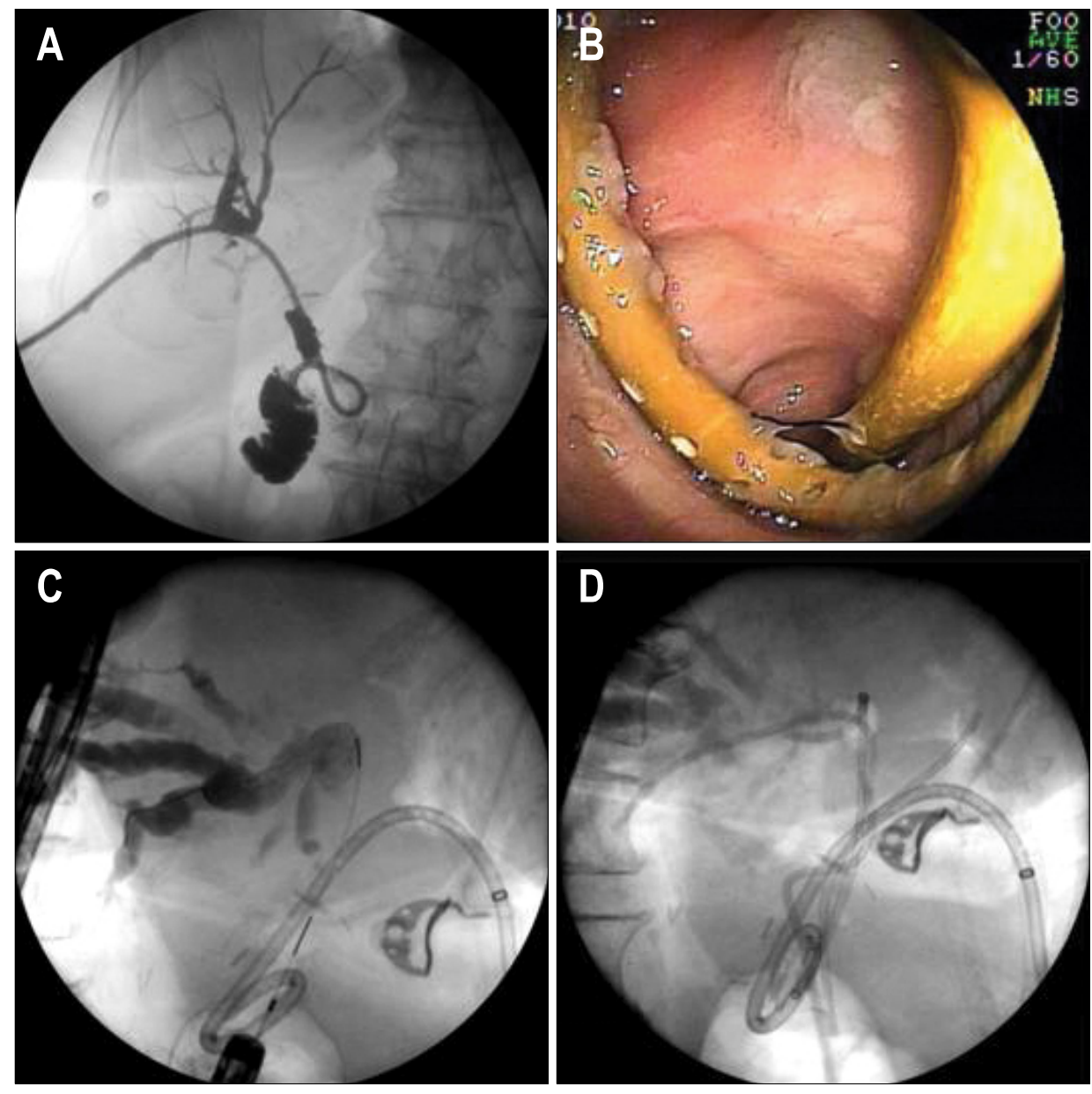

Fig. 6. Percutaneous transhepatic biliary drain (PTBD) demonstrating segmental filling of the right intrahepatic ducts (A) in the patient at 3 years post-Whipple for benign intraductal papillary mucinous neoplasm. (B) Endoscopic view of PTBD obtained with a double-balloon enteroscope. (C) Cholangiogram demonstrates a pus-filled, obstructed left system treated with multiple left and right intrahepatic stents (D) in a patient with sepsis and profound coagulopathy. recent prospective, multi-center Dutch study has demonstrated no advantage to preoperative biliary decompression in jaundiced pancreatic cancer patients who undergo radical pancreaticoduodenectomy (Whipple procedure), ${ }^{30,31}$ the same cannot be said of obstructing colon cancer. Conventional treatment of the latter has been diverting colostomy in conjunction with neoplasm resection and formation of a Hartman pouch. Contingent upon fitness for reoperation and presence or absence of metastases, a second surgical procedure is required to restore bowel continuity. A meta-analysis of this approach has documented morbidity up to $60 \%$ and mortality as high as $20 \%$ in this setting. ${ }^{32}$ Insertion of a SEMS to allow bowel decompression and elective surgery, if appropriate, has been associated with improved outcomes and decreased incidence of urgent surgery in poor risk patients or those with metastatic disease (Fig. 5). In a meta-analysis reviewing 10 studies and 451 patients, 244 of whom had attempted stent placement and the reminder surgical decompression, successful stent insertion occurred in 93 percent. $^{33}$ The mean length of hospitalization approximated 8 days less in the stent group $(p<0.001)$, there were fewer complications and decreased need for stoma formation in the stent group $(\mathrm{p}<0.001)$, and lower mortality $(\mathrm{p}=0.03)$. Additional publications based on Decision and Cost Analysis have suggested that colon stenting followed by elective surgery, if indicated, results in $23 \%$ fewer surgeries, an $83 \%$ reduction in stoma formation, lower mean costs, and a lower procedure-related mortality (5\% vs $11 \%$ ) although recent literature suggests longterm complications in a subset of patients in whom colon SEMS have been placed. ${ }^{34}$

In my own, as well as other, institutions, there are a myriad additional interactions including combining endoscopic and laparoscopic resection of submucosal gut tumors, combined endoscopic radiologic and surgical therapies for walled off pancreatic necrosis (Fig. 7), placement of transgastric/enteric stents in individuals with pancreaticocutaneous fistulas, and combined procedures for ectopic variceal bleeding to name only a few (Fig. 4). ${ }^{35-37}$

\section{CONCLUSIONS}

This interdisciplinary interaction has proven invaluable 

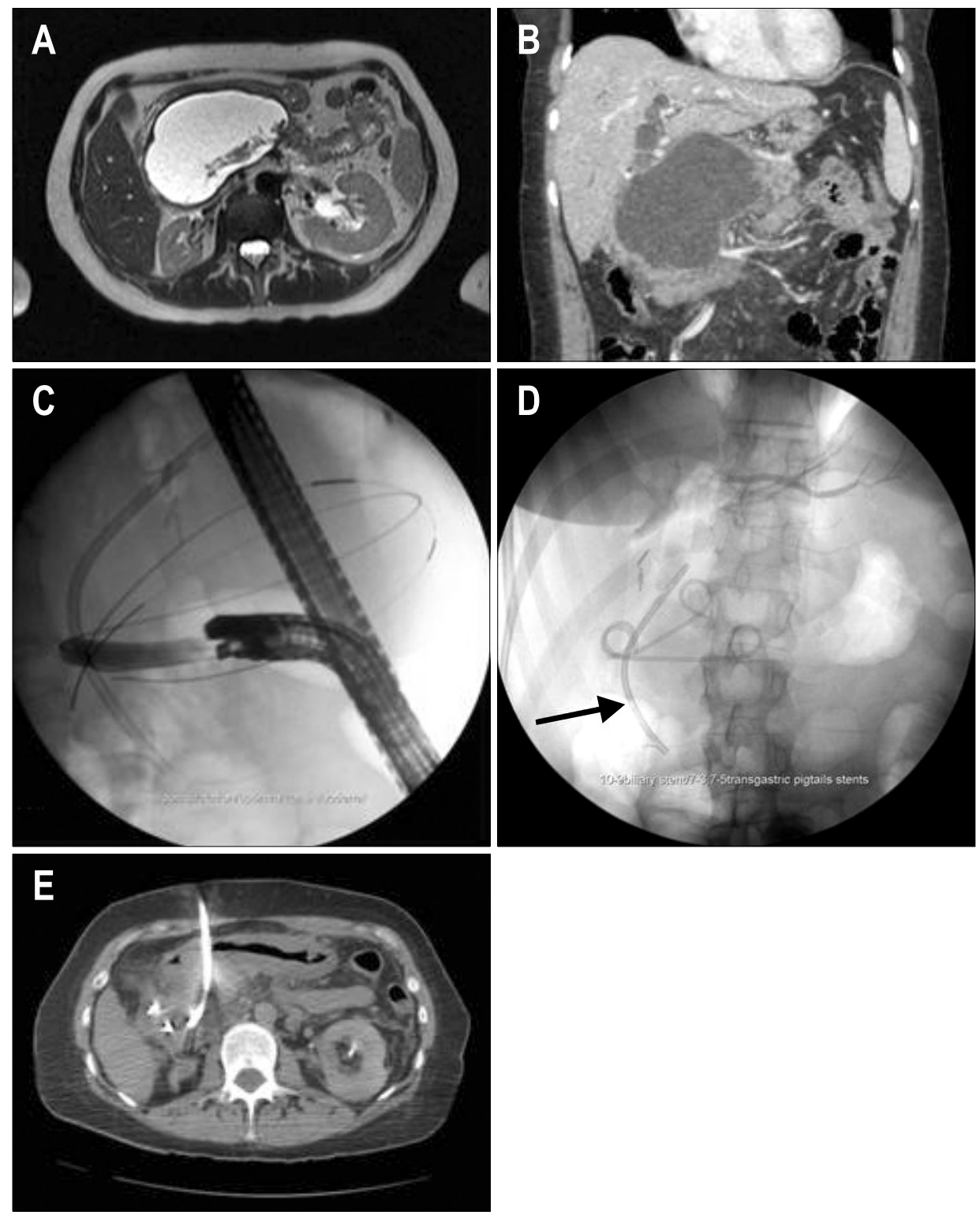

Fig. 7. Magnetic resonance imaging showing a walled-off pancreatic necrosis (A). Computed tomography demonstrates a high-grade biliary obstruction (B) treated with a biliary stent (arrow) and transduodenal pigtail-stent placement (C, D). Note subsequent percutaneous placement of an IR drain to allow irrigation and evacuation of necrotic debris (E). This combined therapy prevents the development of a pancreaticocutaneous fistula.

in the case of patients both locally and in institutions worldwide. Whether we compete, cooperate in an interdisciplinary fashion, learn from each other, or evolve into a proceduralist with backgrounds in all of the disciplines noted is likely a consequence of board certification, institutional accreditation, and individual mind set. However we evolve, our goal should be that which serves our patient best. It is the camaraderie and intellectual cross-fertilization developed and fostered by the SGI that will help to facilitate this goal.

\section{REFERENCES}

1. Martinez Rodrigo J, Marti-Bonmati L, Segarra Medrano A, et al. Certification guidelines of the Spanish Society of Diagnostic Radiology (SERAM) and the Spanish Society of Vascular and Interventional Radiology (SERVEI) concerning requirements and equipment in vascular and interventional radiology. Radiologia 2007;49:381-387.

2. Desser TS. Simulation-based training: the next revolution in radiology education? J Am Coll Radiol 2007;4:816-824.

3. Hamad GG, Curet M. Minimally invasive surgery. Am J Surg 2010;199:263-265. 
4. Stefanidis D, Hope WW, Korndorffer JR Jr, Markley S, Scott DJ. Initial laparoscopic basic skills training shortens the learning curve of laparoscopic suturing and is cost-effective. J Am Coll Surg 2010;210:436-440.

5. Bittner JG 4th, Coverdill JE, Imam T, Deladisma AM, Edwards MA, Mellinger JD. Do increased training requirements in gastrointestinal endoscopy and advanced laparoscopy necessitate a paradigm shift? A survey of program directors in surgery. J Surg Educ 2008;65:418-430.

6. Dray X, Marteau P. The future of gastrointestinal therapeutic endoscopy: NOTES. Gastroenterol Clin Biol 2009;33:758-766.

7. Horgan S, Cullen JP, Talamini MA, et al. Natural orifice surgery: initial clinical experience. Surg Endosc 2009;23: 1512-1518.

8. Cahill RA. Natural orifice transluminal endoscopic surgery--here and now. Surgeon 2010;8:44-50.

9. Linke GR, Tarantino I, Hoetzel R, et al. Transvaginal rigid-hybrid NOTES cholecystectomy: evaluation in routine clinical practice. Endoscopy 2010;42:571-575.

10. Chow A, Purkayastha S, Paraskeva P. Appendicectomy and cholecystectomy using single-incision laparoscopic surgery (SILS): the first UK experience. Surg Innov 2009;16:211217.

11. Chamberlain RS, Sakpal SV. A comprehensive review of single-incision laparoscopic surgery (SILS) and natural orifice transluminal endoscopic surgery (NOTES) techniques for cholecystectomy. J Gastrointest Surg 2009;13:17331740.

12. Mofid H, Zornig C. Single-access surgery laparoscopic cholecystectomy and appendectomy. Surg Technol Int 2010;19:61-64.

13. Hu H, Zhu J, Wang W, Huang A. Optimized transumbilical endoscopic cholecystectomy: a randomized comparison of two procedures. Surg Endosc 2010;24:1080-1084.

14. Pang SH, Lau JY. Hemostasis. In: Classen M, Tytgat G, Lightdale C, eds. Gastroenterological endoscopy. New York: Thieme, 2010:272-280.

15. Waye JD, Saunders B, Sano Y, Tanaka S. Polypectomy. In: Classen M, Tytgat G, Lightdale C, eds. Gastroenterological endoscopy. New York: Thieme, 2010:299-322.

16. Loffroy R, Guiu B. Role of transcatheter arterial embolization for massive bleeding from gastroduodenal ulcers. World J Gastroenterol 2009;15:5889-5897.

17. Kavanagh PV, vanSonnenberg E, Wittich GR, Goodacre BW, Walser EM. Interventional radiology of the biliary tract. Endoscopy 1997;29:570-576.

18. Ng PC. Re: Surg Endosc (2009) 23:1142-1145, DOI: 10.1007/s00464-009-0382-x (published online 5 March 2009). Erica P. Podolsky, Steven J. Rottman, Paul G. Curcillo II. Single Port Access (SPA) gastrostomy tube in patients unable to receive percutaneous endoscopic gastrostomy placement. Surg Endosc 2010;24:970.

19. Singal AK, Dekovich AA, Tam AL, Wallace MJ. Percutaneous transesophageal gastrostomy tube placement: an alternative to percutaneous endoscopic gastrostomy in patients with intra-abdominal metastasis. Gastrointest Endosc 2010; 71:402-406.

20. Loberant N, Notes Y, Eitan A, Yakir O, Bickel A. Comparison of early outcome from transperitoneal versus transhepatic percutaneous cholecystostomy. Hepatogastro- enterology 2010;57:12-17.

21. Tang CN, Siu WT, Ha JP, Tai CK, Tsui KK, Li MK. Laparoscopic biliary bypass--a single centre experience. Hepatogastroenterology 2007;54:503-507.

22. Itoi $\mathrm{T}$, Coelho-Prabhu $\mathrm{N}$, Baron $\mathrm{TH}$. Endoscopic gallbladder drainage for management of acute cholecystitis. Gastrointest Endosc 2010;71:1038-1045.

23. Shami VM, Kahaleh M. Endoscopic ultrasound-guided cholangiopancreatography and rendezvous techniques. Dig Liver Dis 2010;42:419-424.

24. Kim YS, Gupta K, Mallery S, Li R, Kinney T, Freeman ML. Endoscopic ultrasound rendezvous for bile duct access using a transduodenal approach: cumulative experience at a single center. A case series. Endoscopy 2010;42:496-502.

25. La Greca G, Barbagallo F, Sofia M, Latteri S, Russello D. Simultaneous laparoendoscopic rendezvous for the treatment of cholecystocholedocholithiasis. Surg Endosc 2010; 24:769-780.

26. Badaoui A, Malherbe V, Rosiere A, De Ronde T. ERCP by laparoscopic transgastric access and cholecystectomy at the same time in a patient with gastric bypass who was seen with choledocholithiasis. Gastrointest Endosc 2010;71:212214.

27. Gutierrez JM, Lederer H, Krook JC, Kinney TP, Freeman ML, Jensen EH. Surgical gastrostomy for pancreatobiliary and duodenal access following Roux en Y gastric bypass. J Gastrointest Surg 2009;13:2170-2175.

28. Weber A, Prinz C, Gerngross C, et al. Long-term outcome of endoscopic and/or percutaneous transhepatic therapy in patients with biliary stricture after orthotopic liver transplantation. J Gastroenterol 2009;44:1195-1202.

29. La Greca G, Barbagallo F, Di Blasi M, et al. Laparo-endoscopic "Rendezvous" to treat cholecysto-choledocolithiasis: effective, safe and simplifies the endoscopist's work. World J Gastroenterol 2008;14:2844-2850.

30. van der Gaag NA, Rauws EA, van Eijck $\mathrm{CH}$, et al. Preoperative biliary drainage for cancer of the head of the pancreas. N Engl J Med 2010;362:129-137.

31. Baron TH, Kozarek RA. Preoperative biliary stents in pancreatic cancer--proceed with caution. N Engl J Med 2010; 362:170-172.

32. Keymling M. Colorectal stenting. Endoscopy 2003;35:234238.

33. Targownik LE, Spiegel BM, Sack J, et al. Colonic stent vs. emergency surgery for management of acute left-sided malignant colonic obstruction: a decision analysis. Gastrointest Endosc 2004;60:865-874.

34. Fernández-Esparrach G, Bordas JM, Giráldez MD, et al. Severe complications limit long-term clinical success of self-expanding metal stents in patients with obstructive colorectal cancer. Am J Gastroenterol 2010;105:1087-1093.

35. Ross A, Gluck M, Irani S, et al. Combined endoscopic and percutaneous drainage of organized pancreatic necrosis. Gastrointest Endosc 2010;71:79-84.

36. Gardner TB, Chahal P, Papachristou GI, et al. A comparison of direct endoscopic necrosectomy with transmural endoscopic drainage for the treatment of walled-off pancreatic necrosis. Gastrointest Endosc 2009;69:1085-1094.

37. Isayama H, Yamamoto K, Mizuno S, et al. NOTES and endoscopic pancreatic necrosectomy for the GI endoscopist. J Hepatobiliary Pancreat Surg 2009;16:270-273. 